\title{
La cuestión de la tierra: el despojo y la posesión en el trabajo etnográfico
}

\author{
The Question of Land: Dispossession and Possession \\ in Ethnographic Inquiry
}

\author{
Meghan L. Morris \\ Departamento de Antropología, Universidad de Chicago \\ mlmorris@uchicago.edu
}

\section{RESUMEN}

En Colombia, el concepto de despojo ha ido tomando fuerza en espacios sociales, burocráticos y académicos. En este artículo atiendo el Ilamado de Gillian Hart (2006) a mantener un compromiso con la comprensión del despojo, que considere conjuntamente sus significados dispares y sus hechos materiales mediante la etnografía, a fin de construir conceptos que ayuden a entender la complejidad. Con base en el trabajo etnográfico llevado a cabo en Urabá, un sitio a menudo considerado como "emblemático" del despojo, tomo las posibilidades y límites del despojo como herramienta conceptual para entender las complejidades del conflicto en la región. Sugiero que complementar el despojo con otras herramientas conceptuales, como la posesión, podría llevar a una comprensión más profunda de la cuestión de la tierra en una región como Urabá y a la construcción de soluciones políticas más duraderas.

Palabras clave: despojo, posesión, tierra, Colombia.

\begin{abstract}
$\overline{\text { ABSTRACT }}$
The concept of dispossession has taken on new force in Colombia, across social, bureaucratic, and academic spaces. In this article, I follow Gillian Hart's (2006) call for an engagement with dispossession that considers its disparate meanings and material facts together, in order to build concepts that help understand complexity through ethnography. Drawing on ethnographic fieldwork conducted in Urabá, a site often considered to be "emblematic" of dispossession, I consider the possibilities and limits of dispossession as a conceptual tool for understanding the complexities of the conflict in the region. I suggest that complementing dispossession with other conceptual tools, such as possession, could allow for a deeper understanding of the question of land in a region like Urabá, and the construction of more lasting political outcomes.
\end{abstract}

Keywords: dispossession, possession, land, Colombia. 


\section{Introducción}

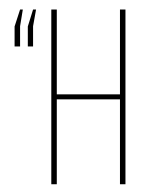

ace un tiempo, dos años, no existía el despojo”. El director de la Unidad de Restitución de Tierras (URT), Ricardo Sabogal, estaba ávido por describir el progreso de la unidad durante sus dos primeros años de actividades. Parado frente a funcionarios públicos, académicos, investigadores, periodistas y políticos reunidos en el Hotel Tequendama en Bogotá, Sabogal recordó la notable ausencia de información sobre el despojo antes de que comenzara el proceso de restitución de tierras para las víctimas del conflicto:

Existía en las notas de prensa. No existían los jueces agrarios o de restitución... hoy hay jueces y ya hay providencias judiciales. Hay sentencias, sentencias que se producen a diario. En ese sentido la restitución pasa de ser números a ser nombres y apellidos, historias de vida, lo cualitativo de este proceso.

Enfatizó, además, la importancia de la restitución para el desarrollo rural y una "nueva justicia” más fundamentada en la palabra de las víctimas que en la de los victimarios.

Claramente, Sabogal no estaba diciendo que en Colombia no había robos de tierras antes del 2012. Aquello a lo que Gillian Hart (2006) se refiere como los hechos materiales del despojo estaba ya en las noticias y en la conciencia pública, y eran los cimientos sobre los que se había erigido la sección dedicada a la restitución de tierras en la Ley 1448 de 2011 (Ley de Víctimas y Restitución de Tierras) y la misma URT. Esos hechos materiales también estaban presentes en el establecimiento de las Comisiones Regionales para la Restitución de Bienes por parte de la Ley de Justicia y Paz (Ley 975 de 2005), así como en la creciente atención institucional a la población desplazada que impulsó la Sentencia T-025 de 2004 sobre desplazamiento forzado ${ }^{1}$. Aunque a finales de los 2000 el concepto empezó a circular en espacios institucionales asociados con la Ley de Justicia y Paz y con el seguimiento a la Sentencia T-025 de 2004², el despojo no había existido en estos términos

Para mayor información sobre los efectos institucionales de la Sentencia T-025 de 2004, véase Rodríguez y Rodríguez (2010).

Ni la Ley de Justicia y Paz ni la Sentencia T-025 de 2004 utilizan el término despojo. Sin embargo, el uso institucional de ese término empieza a aparecer como parte del seguimiento tanto a la ley como a la sentencia. Un ejemplo de este uso asociado con la Ley de Justicia y Paz se encuentra en el informe de la Comisión Nacional de Reparación y Reconciliación, "El despojo de tierras y territorios. Aproximación conceptual", que se dedica explícitamente a la conceptualización del término (CNRR 2009). En el caso del seguimiento a la Sentencia T-025 de 2004, el uso del concepto despojo se encuentra en el VI Informe de la Comisión de 
- como agenda de gobierno, como lenguaje burocrático y como base jurídica para la condición de víctima-ni tenía los significados y consecuencias que tiene en la coyuntura actual en Colombia.

En torno a este cambio giran algunas de las motivaciones de los editores de este número para compilar una colección de artículos sobre el despojo. Me imagino que ese mismo cambio estimuló a otros autores, tal y como me sucedió, a hacer investigación etnográfica que de una u otra forma aborde el concepto de despojo, un concepto cada vez más importante en el discurso político colombiano, a pesar de que sus hechos materiales hayan estado en el paisaje político desde hace mucho tiempo. Pero tomar el despojo como objeto de investigación antropológica es una tarea particularmente difícil. El despojo es, por un lado, un concepto usado por los movimientos sociales y políticos para comprender formas de saqueo y así ha aparecido en las noticias sobre el conflicto y en las concepciones más coloquiales de robo. Por otro lado, es una categoría académica presente desde hace mucho tiempo en disciplinas como la geografía, los estudios agrarios y la antropología, y ha hecho parte de teorías críticas que abarcan desde formas específicas de acumulación de tierras hasta la economía política en un sentido amplio. En Colombia, el surgimiento del despojo como categoría de la política formal y de la construcción del Estado - un hecho que Sabogal atribuye a la recolección estatal de información y a la creación de instituciones- tuvo lugar en un abigarrado campo de significados en el que los lenguajes coloquiales, académicos y burocráticos se entrelazaron de formas que tienen muchísima relevancia política ${ }^{3}$. Aunque en estos registros hay una comprensión común del despojo como el acto de quitarle la tierra a alguien - la misma que utilizo en este artículo-, a veces difieren en la manera como entienden las implicaciones de dicho acto y en las consecuencias conceptuales del despojo.

En un artículo sobre el despojo, Gillian Hart (2006) hizo un llamado a comprometerse con una aproximación que permitiera entender etnográficamente tanto sus significados dispares como sus hechos materiales. Su aspiración era que tal aproximación no solo abarcara descripciones empíricas del despojo, sino "conceptos concretos que se ajusten a la complejidad con la que se está tratando

Seguimiento a la Política Pública sobre Desplazamiento Forzado (Comisión de Seguimiento 2008), así como el Auto 008 de 2009, en el cual la Corte Constitucional constató la persistencia del estado de cosas inconstitucional con respecto a la población desplazada y ordenó la reformulación de la política de tierras, para lo cual citó el VI Informe de la Comisión de Seguimiento.

3 Para una discusión sobre ese entrelazamiento y un llamado a una conceptualización del despojo que recurra explícitamente a estos campos diversos de significado empírico, teórico y burocrático, véase CNRR $(2009,26)$. 
de lidiar” (984). La invitación de Hart motiva varias de las preguntas que orientan este artículo. ¿El despojo, como concepto, se ajusta a la complejidad que buscamos entender en la coyuntura actual en Colombia? ¿Cuáles son sus posibilidades y sus límites como herramienta conceptual para comprender el arco de un conflicto que cada vez más se describe en esos términos?

Para analizar estas preguntas me inspiro en la larga historia de trabajo antropológico sobre la propiedad, que ha hecho énfasis en las maneras en que la propiedad puede servir de punto de entrada a fenómenos sociales y políticos más amplios. Los trabajos clásicos en este campo analizan cómo los conceptos de la propiedad emergen y son estructurados por la sociedad, al mismo tiempo que la estructuran. Esto se observa desde los esfuerzos de Bronislaw Malinowski por entender los sistemas políticos y de parentesco de los Trobriand a través de sus estructuras de tenencia ([1935] 1978) hasta trabajos más recientes que consideran la relación de la propiedad con la vida social (véanse, por ejemplo, Verdery y Humphrey [2004] y Von Benda-Beckmann et al. [2006]). Si bien un análisis del concepto de despojo necesariamente abarca fenómenos que van más allá de la propiedad tales como la violencia, la antropología de la propiedad provee una guía metodológica para el análisis y la construcción de conceptos sustentados etnográficamente.

Considero las preguntas de investigación de cara al trabajo de campo etnográfico que realicé entre el 2012 y el 2014 en la región del Urabá, en el noroeste de Colombia, frecuentemente descrita como un sitio "emblemático" del despojo4. Desde allí trazo la historia de varias formas de lucha por la tierra que son claves para pensar las posibilidades y los límites presentados por la aparición del despojo como una forma de narrar y comprender la historia de esas luchas. Así, entiendo esas luchas como parte de un campo amplio de disputa por la tierra y por la política agraria, identificada por mis interlocutores en Urabá como la cuestión de la tierra, concepto que las ciencias sociales y las instituciones también han utilizado de manera recurrente ${ }^{5}$. A diferencia de la mayoría de las investigaciones

4 Para una definición del Urabá como un sitio emblemático por sus niveles de despojo, véase el informe de rendición de cuentas de la URT en Antioquia de 2014 (5). Artículos de prensa nacional y de organizaciones de la sociedad civil también identifican a Urabá como un lugar emblemático de despojo; véase por ejemplo, "Restitución de tierras llegará a más municipios de Antioquia en 2016" (El Tiempo, 30 de diciembre del 2015. http://www.eltiempo.com/colombia/ medellin/restitucion-de-tierras-llegara-a-mas-municipios-de-antioquia-en-el-2016/16470073) y "Continúan ataques en contra de víctimas reclamantes de tierras en Urabá" (Instituto Popular de Capacitación, 8 de junio del 2016. http://www.ipc.org.co/agenciadeprensa/index. php/2016/06/08/continuan-ataques-victimas-reclamantes-tierras-uraba/).

5 Para ejemplos de la utilización de la expresión cuestión de la tierra en las ciencias sociales y las instituciones, véase por ejemplo la convocatoria del presente dosier (ICANH 2015) y CNMH (2013b). Tal como sucede en las calles de Urabá, muchas veces en las ciencias sociales y en 
sobre tierra en Urabá, me centro no solo en las luchas del campo sino también en las del espacio urbano, elemento crucial en la historia política y social de la tierra en esa región durante la segunda mitad del siglo XX.

En esta investigación etnográfica, considero aquello que el despojo revela y oculta en comparación con otros conceptos que han surgido en los registros locales y burocráticos para entender y narrar la historia de la lucha por la tierra. También rastreo otras categorías que cobran importancia junto al despojo en la narrativa sobre la impugnación de la tierra, en particular, la posesión. Como parte de mi análisis, considero los hechos materiales y los significados atados a estos conceptos, en tanto medios fundamentales para hacer reclamos sobre la tierra y como formas de conocimiento burocrático y legal. Me aproximo a Urabá no como una región desde la cual se puede generalizar, sino como un punto de entrada para pensar el despojo y, ojalá, construir preguntas productivas en otros sitios y situaciones.

\section{Urabá y la cuestión de la tierra}

Durante mi primer viaje de investigación a Colombia, después de que fuera sancionada la Ley de Víctimas, comenté con varios funcionarios estatales en Bogotá y Medellín mi interés en hacerles seguimiento a algunos casos de restitución en Urabá. Había trabajado por primera vez en esa región a finales de la década del 2000. Para entonces, habitantes y funcionarios locales elaboraban un proyecto piloto de restitución de tierras, impulsado en el ámbito institucional por la oficina regional de Antioquia de la Comisión Nacional de Reparación y Reconciliación ${ }^{6}$. Este proyecto piloto serviría más adelante de guía parcial para la restitución de tierras a escala nacional, lo que convirtió al Urabá en un lugar crucial para evaluar cómo se podría implementar la restitución. Mis conversaciones

las instituciones se usa esta expresión para identificar el tema de tierras o el problema de la política de tierras. Sin embargo, no existe una genealogía conceptual del uso de esta noción en estos distintos campos; una genealogía de este tipo va más allá del alcance de este artículo, pero sería un tema importante de investigación.

6 La Comisión Nacional de Reparación y Reconciliación (CNRR), creada por la Ley de Justicia y Paz, tuvo el mandato de coordinar las actividades de las Comisiones Regionales para la Restitución de Bienes (CRRB). La primera CRRB establecida en el país fue la de Antioquia; esta fue la institución que recibió muchos de los casos documentados en el proyecto piloto de Urabá. La CNRR también realizó dos proyectos pilotos adicionales, uno en el corregimiento de Mampuján, en el municipio de María La Baja en Bolívar, y el otro en el corregimiento de Chengue, en el municipio de Ovejas en Sucre. 
con los funcionarios en el 2012 revelaron que, apenas unos meses después de la aprobación de la Ley de Víctimas, la noción de despojo ya se había institucionalizado. En respuesta a mi interés de trabajar en Urabá, funcionarios de instituciones como la URT, el Programa de las Naciones Unidas para el Desarrollo (PNUD) y el Instituto Colombiano de Desarrollo Rural (Incoder) ${ }^{7}$ coincidían en un punto: lo que caracterizó al Urabá fue la densidad del despojo. Me contaron que esa fue una diferencia clave con otros lugares - por ejemplo, con el oriente antioqueño que se caracterizó, según ellos, por el abandono y el retorno- e hizo de Urabá un sitio fundamental para la restitución. En definitiva, el criterio densidad del despojo, usado para la microfocalización ${ }^{8}$ en una zona donde habría restitución, rápidamente se convirtió en la narrativa burocrática dominante de la región.

El que esa forma de narrar el Urabá se hiciera tan común en tan poco tiempo me llamó la atención. Pensé en todas las descripciones que había oído sobre la región unos cuantos años antes - un lugar marcado por las masacres, los bananos, la guerra, el contrabando-y por los problemas en torno a la tierra que eran entendidos en términos diferentes. En mi investigación previa, los residentes de Urabá con quienes tuve la oportunidad de conversar a menudo se quejaron de las pérdidas de tierra, y me dijeron que debería dedicarme a comprender el problema de la tierra en Urabá y no al proyecto de investigación en el que trabajaba entonces sobre los casos presentados a las cortes federales de Estados Unidos contra Chiquita Brands. Sin embargo, ese asunto, que se suponía debía estudiar, no era descrito como despojo y mucho menos como densidad del despojo, sino como la cuestión de la tierra.

Esta distinción podría parecer irrelevante. ¿No será que en últimas el despojo y la cuestión de la tierra describen el mismo fenómeno? ¿No se trata de los mismos hechos materiales, de la pérdida generalizada de pequeñas fincas y parcelas de familias rurales de Urabá, en el contexto de la violencia paramilitar a finales de los noventa, que más tarde los grandes propietarios consolidarían en las haciendas ganaderas y las plantaciones que hoy en día se extienden por gran parte del paisaje de Urabá? Durante todos mis años de trabajo de campo, y en docenas de entrevistas e historias de vida de reclamantes de tierras en Urabá, he escuchado relatos sobre este tipo de despojo muchas más veces de las que puedo contar. Esos relatos, sin embargo, a menudo son piezas de una narrativa mucho más extensa sobre luchas en la región en torno a la cuestión de la tierra, aunque

7 El Incoder era una de las instituciones encargadas de la política rural de Colombia hasta que empezó su proceso de liquidación en el año 2015.

8 La microfocalización, para efectos de restitución de tierras y según la URT, es un mecanismo de selección de casos para ser atendidos prioritariamente. 
estas no hayan sido narradas exclusivamente como despojo. Basada en algunas de esas entrevistas e historias de vida, me planteo si la narración de Urabá como un lugar caracterizado por el despojo captura adecuadamente la historia política y social que subyace a la cuestión de la tierra en la región.

Los reclamantes de tierras entrevistados que llegaron primero al Urabá lo hicieron durante los años sesenta. Aquella fue una época de cambios dramáticos para la región, y la industria bananera creció y se consolidó. Durante mucho tiempo la zona había sido un lugar de proyectos extractivos (Parsons 1967; Steiner 2000), que incluían desde la cosecha de tagua y la tala de bosques hasta los intentos agroindustriales. También desde el siglo XVI había sido una región caracterizada por lo que María Teresa Uribe (1992) describe como una colonización permanente. Pero los sesenta cambiaron su orientación y produjeron una explosión demográfica. Miles de personas, sobre todo de Córdoba y del Chocó, migraron al Urabá para trabajar como obreros de la industria bananera. Profesionales y empresarios de clase media y media alta también llegaron a la región por la industria: algunos para trabajar como agrónomos o como administradores y otros para invertir en tierras de producción bananera a mediana escala. Un poco más tarde también invertirían en tierras personas que habían obtenido su dinero en el negocio del contrabando o del narcotráfico (Ortiz 1995, 2007). Mientras que Chiquita Brands comenzaba la producción de banano de exportación en la región, estos inversionistas - algunos llegados desde Santa Marta con experiencia en la industria y otros sin experiencia previa, pero con dinero para invertir- fueron muy importantes en el crecimiento del sector durante las décadas siguientes. Al mismo tiempo, algunos campesinos llegaron a la región, no para trabajar en la industria bananera en sí, sino en busca de tierra para cultivos agrícolas básicos o para criar ganado.

La migración desde Antioquia hacia Urabá se incrementó en los sesenta, después de que se construyera la carretera de Medellín a Turbo (Ortiz 1995, 2007)9. Los antioqueños, entonces, se sumaron al flujo histórico de los migrantes hacia Urabá desde el Chocó, Córdoba y el resto de la costa caribe. Los migrantes muchas veces entendieron la región como un lugar de abundancia: de tierras, trabajo y posibilidades. La ubicación estratégica de la región entre el Caribe y el Pacífico, así como sus fuentes hídricas, tierras fértiles y otros recursos naturales, la llevaron a ser nombrada como "la mejor esquina de América"10. Ser la mejor esquina

9 Para más detalles sobre la historia de la construcción de la carretera entre Medellín y Turbo, crucial para la historia del Urabá durante el siglo XX, véase Parsons (1967).

10 Para ejemplos del uso de este nombre por comentaristas fuera de Urabá, véase, por ejemplo Hinestroza (2015) y para una exploración etnográfica, Aparicio (2009). 
de América también significaba que Urabá era un lugar de desarrollo de otras industrias que crecieron al lado de la bananera, tales como el contrabando y el narcotráfico.

Fue así que Urabá se convirtió en un sitio de oportunidades y de sueños en múltiples niveles: trabajo, ganancias y tierras. La tierra, en particular, fue objeto de admiración debido a su fertilidad y a su aparente abundancia. Los campesinos que llegaron desde Córdoba durante los sesenta me contaron que sus familias se ubicaron en el suroeste de Urabá, en el borde oriental del Chocó, porque la tierra tenía fama de ser muy fértil. Emilio ${ }^{11}$, cuya familia había llegado en los sesenta y había establecido una pequeña finca familiar en el Urabá chocoano, relató:

Mi papá, desde muy joven, él soñaba con el Chocó. Él soñaba con el Chocó, y que el Chocó tenía una fama, y el Chocó en verdad, en realidad, son tierras muy fértiles y muy buenas. Y él soñaba con eso y nos metimos... por allá no había sino única y exclusivamente selva, selva y animales... eso era totalmente una belleza, porque la verdad es que uno como campesino, no sé, a uno le encanta... esto no tiene nombre para mí, esto es una belleza, es un paraíso.

Ese asombro por la tierra emergió también en las conversaciones con los bananeros de mediana escala como un aspecto crucial a la hora de decidir invertir en Urabá. Dos propietarios de plantaciones, Germán y Miguel, me describieron esa relación con la tierra como parte de la vocación de la gente que llegó para invertir en ella. Germán dijo:

Eso es una cosa pues que no se la creen a uno. Pero uno camina una tierra y uno por encima de la bota uno sabe cuándo la tierra es buena. De tanto, pues, quererla y de tanto pasear tierras y mirar cosas. Pero uno, uno, uno... esa vocación por la tierra, eso es muy especial. Eso es muy especial.

Miguel estuvo de acuerdo y señaló: "Sí. Y eso es interesante que la gran mayoría de los que vinieron acá tenían esa, algo de esa... de esa vocación que no eran simplemente inversionistas”. Germán enfatizó: “Lo que es fundamental para la gente de aquí es la querencia por la zona. Por la tierra”.

Los inversionistas que arribaron a la región durante los primeros años de la industria bananera adquirieron la mayoría de sus tierras en el centro de Urabá, una región que llegó a estar dominada por plantaciones de banano. Aunque Chiquita Brands había sido propietaria de tierras bananeras en Magdalena, en 
Urabá, durante el desarrollo de esa industria en los sesenta, decidió facilitar la adquisición y titulación de tierras a los productores de la región, manteniéndose como una comercializadora de los bananos producidos localmente (Bucheli 2005). Uno de estos bananeros, Mauricio, relató lo que llamó un "experimento" de Chiquita:

Chiquita hizo un plan estratégico para desarrollar 15.000 hectáreas, puso el recurso a través de la Asociación Financiera Colombiana y promovieron un proyecto para que la gente se vinculara. Invitaron. Entonces, por eso llegaron pilotos, dentistas, agrónomos, choferes... como mi papá y mi abuelo.

Los esfuerzos de Chiquita por evitar conflictos con los obreros y por gestionar las demandas de los bananeros locales a través de este "experimento" crearon una apertura que dio lugar a una ola de adquisiciones de tierras en la región y sentaron las bases para que una nueva élite local se desarrollara.

Los campesinos que llegaron a la región a establecer pequeñas fincas encontraron una franja de plantaciones bananeras en gran parte de la zona central de Urabá. Muchos de ellos se fueron al sur y al oeste, donde aún quedaban algunos baldíos y donde los suelos, que tenían contenidos más altos de arcilla, no eran aptos para la expansión de la producción de banano. Algunos de esos campesinos ocuparon los baldíos y los trabajaron, y después titularon sus fincas gracias a las campañas de adjudicación del Instituto Colombiano de la Reforma Agraria (Incora) ${ }^{12}$. Otros las obtuvieron comprando el "trabajo" de personas que habían talado el bosque - lo que con frecuencia mencionaron como una "mejora”- y tomaron posesión de la tierra. La posesión, como término jurídico, fue adaptado por la gente local para describir el acto de establecerse en un pedazo de tierra, un acto que muchos sabían que podría tener efectos jurídicos, aunque a veces no eran claros $^{13}$.

Los baldíos son bienes públicos de la Nación. Incora era - tal como el Incoder hasta su liquidación- la institución encargada de la adjudicación de baldíos a personas que hubieran ocupado el terreno y explotado una parte de este.

Tal como sucede con el despojo, términos como posesión, ocupación e invasión circulan tanto en los léxicos locales como en los académicos y jurídicos. Jurídicamente, cada uno de ellos está definido en el Código Civil o en el Código Penal. La posesión se define como "la tenencia de una cosa determinada con ánimo de señor o dueño, sea que el dueño o el que se da por tal, tenga la cosa por sí mismo, o por otra persona que la tenga en lugar y a nombre de él. El poseedor es reputado dueño, mientras otra persona no justifique serlo" (Código Civil, art. 762); "por la ocupación se adquiere el dominio de las cosas que no pertenecen a nadie, y cuya adquisición no es prohibida por las leyes o por el derecho internacional" (Código Civil, art. 685); y, en cuanto a la invasión, se trata de una situación en la cual una persona invade terreno "con el propósito de obtener para sí o para un tercero provecho ilícito" (Código Penal, art. 263). La utilización coloquial de estas categorías se hace muchas veces con el conocimiento de que son de carácter legal con efectos jurídicos, aunque ese conocimiento es con 
Lo que en los sesenta era apenas un puñado de agricultores, en los setenta y ochenta se fue convirtiendo en pueblitos rodeados por fincas pequeñas. José Miguel, un campesino que llegó con su familia en los setenta, describió cómo se propagó la fama de la región a través de lo que los locales llamaban la posesión ${ }^{14}$ :

Se vinieron las familias primero y esas familias les iban dando la información a las personas que querían trabajar allá... y se venían, y se venían metiendo, se venían metiendo. Entonces, cuando las familias llegaron acá, a estos predios que están aquí, se posesionaban de ese predio... cada quien iba cogiendo su pedazo... hacían sus trochas y clavaban, que todavía a la fecha están unos palos de matarratón en los linderos... y con eso se respetaba la gente antigua.

La ocupación de baldíos y la posesión también estuvieron acompañadas de otras formas de acceso a la tierra ${ }^{15}$, en particular, la invasión ${ }^{16}$. Aunque las invasiones rurales fueron una estrategia común usada en toda la región, tomaron distintas formas en diferentes periodos. Las invasiones de los sesenta en el centro del Urabá fueron llevadas a cabo por diversos actores: campesinos que buscaban establecer pequeñas parcelas y hombres de negocios que querían tomar posesión de tierras fértiles para el cultivo del banano. Clara Inés García describe un cambio en este patrón a finales de los sesenta, cuando esas invasiones comenzaron a estar cada vez más organizadas por los sindicatos o por las asociaciones que las apoyaban (García 1996, 82-84).

A comienzos de los ochenta, la creciente participación de la guerrilla en las invasiones marcó otro cambio. La guerrilla las aprovechó para ampliar su

frecuencia incompleto. En este artículo los empleo como términos locales que emergieron de la etnografía, cada uno con una clara referencia a un término jurídico, pero a veces con significados que difieren de este.

14 Tal como el significado jurídico, la posesión como término local describe una amplia gama de actos y formas de acceder a la tierra. Los campesinos que se establecieron en un pedazo de tierra a través de lo que llamaron la posesión muchas veces lo hicieron con la intención de que tuviera efectos jurídicos. Como abogada, en ocasiones los campesinos de la región me preguntaron por el número de años después de los cuales una posesión se podría convertir en un título. Aunque manifestaron un poco de confusión entre los efectos jurídicos de la posesión y los de la prescripción - a través de la cual se pueden adquirir tierras ajenas bajo ciertas condiciones, una de ellas, la posesión por cierto lapso (Código Civil, arts. 2512, 2518, 2528-2529) —, sabían claramente que existía la posibilidad de adquirir un título mediante la posesión, si se cumplían otros requisitos legales.

15 En este artículo utilizo la expresión formas de acceder a la tierra para describir el conjunto de acciones ejercidas por los campesinos de la región para lograr el acceso a la tierra, entre ellas la posesión, la ocupación y la invasión.

Aunque el significado local del término invasión corresponde en gran parte a su significado jurídico, a veces la palabra se emplea localmente para referirse al acto de ocupar los baldíos, cuando no está claro el estatus jurídico de esos terrenos pero existe el conocimiento por parte de quienes los toman de que no son suyos. 
control y construir una base social y un poder político (García 1996, 85). El Ejército Popular de Liberación (EPL), el grupo guerrillero más involucrado en las invasiones, tenía un comité dedicado a apoyarlas. Un exmiembro del EPL me describió este proceso como de reforma agraria, impulsada tanto por una convicción social como por el deseo de poder territorial, político y social:

El EPL organiza los comités, comités de reforma agraria se llamaban. Era reforma agraria. Entonces tomaba las tierras y las entregaba a los campesinos, entonces la gente se sentía protegida por el EPL... se hacía porque había convicción y bajo su convicción había varias formas de hacerlo... sabes que logras más territorio, logras poder, logras convencimiento, logras apoyar a la gente, logras servir a la gente, todo eso en su conjunto.

Estas invasiones se fueron extendiendo por toda la región, desde el norte de Turbo hasta el municipio de Chigorodó. La más famosa fue, quizá, la de La Coldesa, una plantación de palma de casi 4.000 ha con influencia de agricultores holandeses (Botero 1990), que en 1986 fue invadida por cientos de familias que sembraron plátanos en pequeñas parcelas. Más adelante, varias de esas parcelas fueron compradas por el Incora y entregadas a los invasores (Ortiz 1995, 2007), algunos de los cuales recibieron créditos para la producción de plátano. Entre La Coldesa y otras invasiones en todo el Urabá, se calcula que el EPL asistió a aproximadamente 3.000 familias en la toma de tierras, las cuales muy a menudo fueron usadas para sembrar plátano (García 1996, 90). Aunque esas invasiones eran parecidas a las tomas de tierras apoyadas por la Asociación Nacional de Usuarios Campesinos (ANUC) en Córdoba y Sucre (CNRR 2010b; Fals Borda 1986; Pérez 2010; Zamosc 1987) —y algunos líderes del EPL en Urabá, como Mario Agudelo, habían pertenecido a la ANUC_-, esta fue mucho menos relevante en Urabá que en otras zonas más orientales de la costa caribe. Esto se debió en parte a las tensiones que había entre la ANUC y otros poderosos actores en Urabá, como la guerrilla de las Fuerzas Armadas Revolucionarias de Colombia (FARC) y el Partido Comunista (Agudelo 2005, 26-32).

Mientras la ocupación, posesión e invasión de tierras rurales aumentaba, también lo hacía la invasión de tierras en centros urbanos de Urabá. Las invasiones urbanas estaban compuestas por migrantes, trabajadores de carretera, inquilinos y trabajadores bananeros que habían decidido mudarse desde los campamentos en las plantaciones a la ciudad (García 1996). Los campamentos habían sido parcialmente financiados por los propietarios de las plantaciones bananeras, quienes aportaban dinero a un fondo común para ese fin. Sin embargo, los campamentos se convirtieron en lugares indeseables para vivir y los 
trabajadores querían mejorar sus servicios, estar más seguros y tener viviendas propias. Este se convertiría en un momento sangriento en Urabá, sobre todo para los trabajadores y sindicalistas, que fueron las principales víctimas de las masacres y de la violencia. Las infames masacres de Honduras y La Negra recibieron el nombre de las plantaciones en las que fueron perpetradas: los entonces en ciernes paramilitares llegaron a los campamentos y asesinaron a los trabajadores. Muchos de ellos eran sindicalistas y algunos eran simpatizantes de la Unión Patriótica (R. Romero 2011) ${ }^{17}$.

Los bananeros, algunos de los cuales habían sido secuestrados o cuyos administradores habían sido asesinados por la guerrilla, sintieron mucho miedo de los campamentos, pues los consideraban "caldos de cultivo" para este grupo armado. El temor hizo que se interesaran en que los trabajadores abandonaran los campamentos, por lo cual algunos facilitaron, e incluso incentivaron, las invasiones en las ciudades, permitiéndoles que sacaran materiales de los campamentos y los llevaran a sus invasiones. Uno de ellos describió el sentimiento de los bananeros ante el abandono de los campamentos por parte de los trabajadores:

[...] [los trabajadores] decían: nos vamos. Llévese todo, decía el empresario bananero. Y ellos felices sacando tejas y madera y sanitarios. Entonces, ¿qué dicen los empresarios? Nos quitamos un problema. Ya no hay un enclave guerrillero ahí. Ya no hay gente mimetizada. Ellos mismos quedaron descubiertos.

Los políticos también se beneficiaron de las invasiones urbanas y, en algunos casos, facilitaron la compra de las propiedades invadidas. Dos de las mayores invasiones urbanas de Apartadó -El Concejo y Policarpa- obtuvieron apoyo político de los concejales a la hora de las negociaciones con sus propietarios. Invasiones posteriores, como las iniciales del Barrio Obrero de Apartadó, también fueron coordinadas por líderes sociales que emplearon la falta de vivienda como capital electoral. Alguien que desempeñó un papel clave en las invasiones de Apartadó me describió la convergencia de intereses sociales, políticos y de negocios desarrollada a través de las invasiones:

Encontraron como un mecanismo de que antes de cada proceso electoral, pues como había tanto problema con la vivienda... lo que hacían era, las elecciones del alcalde eran cada dos años, entonces hacían una invasión... líderes sociales hacían invasión, estaba impulsado por ellos... [por ejemplo] invadieron una parte del Barrio Obrero, y entonces llegaba el Concejo y el Concejo tenía que solucionar un problema de orden

17 Miles de miembros de la Unión Patriótica, partido político de izquierda, fueron asesinados durante la violencia en los ochenta y noventa en Urabá. 
público, de vivienda para la gente. Hacían un acuerdo y le compraban ese pedazo al [terrateniente] señor Gaviria... y el [concejal del Partido Liberal] estaba allí. Entonces compraban y la gente solucionaba el problema así, la gente le instalaban... pero a la vez el señor Gaviria se beneficiaba porque vendía el lote, tenían que conectar redes de acueducto y alcantarillado que pasaban cerca o por dentro de su lote.

Pese a todos los intereses que convergieron en las invasiones, estas seguían siendo riesgosas para los invasores. Antes de la salida negociada de la invasión del Barrio Obrero, por ejemplo, la gente involucrada describió los desalojos y los momentos de tensión con el ejército. Alguien recordó:

Se le solicitó a la brigada que no desalojaran, que se hiciera un acuerdo. Y la brigada hizo un acuerdo, de un plazo, no me acuerdo cuántos días fue, para desalojar... lo cierto es que esa noche se metieron el ejército y tumbó las cosas, tumbó las carpas, sacaron, dañaron todo con bulldozer. Eso era una cosa, era como de un supuesto ejercicio de autoridad, ¿no?

Algunos días después, la gente regresó a la invasión y empezó a reconstruir sus ranchos. "Pues unas comenzaban en unas cincuenta hectáreas y otras en otras, entonces el ejército tenía que desagregarse. ¡Y mientras estaban tumbando ranchos por allá los otros estaban haciendo otros en otra parte! Se volvió un juego de gato y ratón”. Finalmente, un obispo que trabajaba en Urabá negoció con la brigada y con el Gobierno nacional y logró que abrieran el camino para que el resto del lote pudiera ser invadido sin obstrucción del ejército. Las personas que participaron en la invasión, sin embargo, enfatizaron que eso tenía su precio y señalaron que, al final, "eso costó el asesinato de dos juntas de acción comunal completas".

La violencia en estas invasiones no cesó tras su establecimiento. Más bien se extendió mientras los diferentes grupos disputaban el control social y político dentro de ellas. Si bien el EPL como grupo guerrillero al principio se enfocó en las invasiones rurales, luego de su desmovilización y transformación en el partido político Esperanza, Paz y Libertad, ayudó a establecer La Chinita, una de las invasiones urbanas más grandes de Apartadó. En 1994, La Chinita pasaría a ser una de las masacres urbanas más infames de toda la historia de Urabá. El Centro Nacional de Memoria Histórica la describe como un acto de las FARC contra los miembros de Esperanza, Paz y Libertad (CNMH 2013a). Así, las tensiones por el control social y territorial se extendieron más allá de los límites rurales y llegaron hasta las invasiones urbanas, que se habían convertido en sitios centrales del poder político y social. 
Durante esta época había un continuo ir y venir de la gente entre las invasiones rurales y urbanas en Urabá. La gente buscaba lotes para la producción de cultivos básicos, mientras tenía su rancho en el centro urbano. Las invasiones urbanas eran activas políticamente y servían de puntos nodales para la organización de invasiones rurales, ya que allí los líderes sociales reclutaban gente para invadir tierras en el campo. Efrén, líder de una invasión rural, describe este proceso:

Había un cura que también nos apoyaba aquí [en Apartadó], y nos dijo, "vean, muchachos, en tal parte hay unas tierritas que son del Estado, iy en estas tierritas ustedes se pueden ir a trabajar! Y el Estado tiene que mirar”. Verdad, nos fuimos, nos metimos a trabajar. Ya después sucedió que buscamos al Incora y por allí iba a medir y todo... Sin embargo, arreglamos con el rico pa pagársela, pa pagársela, aunque la tierra no era de él tampoco. Él también estaba invadido allí.

No obstante, esos movimientos entre invasiones urbanas y rurales no duraron. Efrén contó que trabajó un pedazo de tierra en una invasión rural hasta que la violencia paramilitar lo obligó a regresar a la invasión urbana en Apartadó:

Ya se llegó el momento cuando todo se fracasó otra vez, se acabó como quien dice las invasiones. Ahora fue donde hubo la violencia, que ya hubo la violencia donde los ricos hacían salir a uno ya del monte, llegó ese tiempo ya... Ya los ricos le decían, por ejemplo, llegaban, por allí dos o tres andaban a la casa de uno de noche, y decían: "Bueno, el patrón mandó a decir que cuánto vale su parcela. Que él se la compra. Si no la viuda vende más barato. Que el da tanto por eso y si no la viuda vende más barato”. Entonces nosotros, ya la gente tenía que salir o vender, de todas maneras, que ya era una amenaza... Y los ricos iban tomando todas las tierras... todos tenían que salir del campo.

Con el término la violencia Efrén se refiere al punto máximo de la violencia paramilitar en Urabá, hacia el año 1997, durante el cual hubo un éxodo masivo del campo ${ }^{18}$. Los paramilitares habían aumentado su presencia en la zona, estableciendo un centro de operaciones en Urabá (Romero 2011, 2007), y cada vez más campesinos eran asesinados o amenazados bajo acusaciones de ser colaboradores de la guerrilla. La población comenzó a huir hacia las invasiones urbanas en Urabá o a ciudades como Medellín. Algunos escaparon de la violencia generalizada

18 En Urabá, el uso del término la violencia se refiere en general a un periodo de extrema violencia en la región a finales de los noventa. Se distingue de lo que se conoce a escala nacional como La Violencia, a la cual los habitantes de Urabá se refieren a veces como "la violencia política". Mantengo el uso que las personas a quienes cito en este artículo dan a tal palabra y empleo la violencia para referirme al periodo de finales de los noventa en Urabá. 
a la vez que abandonaron sus tierras, mientras otros eran forzados a venderlas a bajos precios. Algunas ventas se hicieron a través de lo que los campesinos denominaron comisiones, que llegaron con el objetivo de comprar tierras. En ciertos casos llegaron desarmadas y en otros, armadas o acompañadas de individuos a quienes los locales reconocieron como paramilitares. En el transcurso de un par de años hubo un cambio tremendo, con un puñado de grandes terratenientes que se posesionaron y consolidaron la tenencia de la tierra.

Aunque gran parte de dicha tenencia permanece intacta hasta el día de hoy, los campesinos emplearon distintas modalidades para regresar al campo y lograr el acceso a pequeñas parcelas durante los años siguientes a la violencia. La importancia de tales modalidades no radica tanto en las extensiones de tierras tomadas por los campesinos, pocas en comparación con las hectáreas que fueron consolidadas a finales de los noventa, sino en su similitud con las formas históricas de acceder a la tierra en Urabá y con la historia política en la que dichas formas tienen un papel crucial. Los mismos paramilitares facilitaron una de esas modalidades. En algunas áreas de Urabá, estos adoptaron el modelo de la Fundación para la Paz de Córdoba (Funpazcor), por medio de la cual los paramilitares - en este caso los hermanos Castaño—donaron a los campesinos miles de hectáreas en Córdoba para que levantaran fincas y escuelas, en un programa que los Castaño consideraron una "reforma agraria". Más adelante, Funpazcor recuperó muchas de estas "donaciones”, algunas mediante ventas forzadas o amenazas ${ }^{19}$. Este modelo fue liderado y retomado en Urabá por sor Teresa Gómez, hermana adoptiva de los Castaño.

Un campesino involucrado en uno de estos proyectos contó cómo él y su esposa invadieron un pequeño lote rural que usaban para los sembrados antes de su desplazamiento en 1997, cuando se fueron a vivir a una invasión en Apartadó. Después de unos años en Apartadó, escuchó a un vecino decir que alguien estaba promocionando un proyecto para regalar parcelas a personas desplazadas. Asistió a la reunión con el fin de obtener información sobre el proyecto. En su relato, señaló los requisitos necesarios para recibir una parcela: “¿Cuáles eran los requisitos? No tener tierra. No tener casa. Y que no tuvieran donde trabajar y que fuera desplazado". Como tenía un rancho en Apartadó, se le notificó en principio que no cumplía con lo necesario. Pero convenció al líder del proyecto diciéndole:

Sin empleo, sin trabajo... yo no me puedo meter bajo la casa y mirar pa'rriba que desde el techo me caiga comida. Yo necesito tener una

\footnotetext{
19 El relato sobre la finca Santa Paula es un ejemplo de cómo Funpazcor operaba en Córdoba. Véase http://www.verdadabierta.com/component/content/article/48-despojo-de-tierras/4239las-mentiras-de-los-castano-para-despojar.
} 
tierra para producir y tener la comida en sí. Allí lo convencí para que me dieran la parcela.

Se unió, así, a otras docenas de familias que también recibieron parcelas. De cierto modo, esta fórmula tenía rasgos que recordaban las formas en que los grupos guerrilleros habían facilitado el acceso a la tierra mediante sus propias “reformas agrarias”, con las cuales convirtieron la tierra en una vía central de influencia política y social. Valga aclarar que los proyectos paramilitares se diferenciaban de aquellos de manera significativa, sobre todo en que una de sus motivaciones principales era conservar la propiedad. A diferencia de las invasiones apoyadas por el EPL, que fueron promocionadas con la ilusión de que los invasores pudieran algún día obtener el título de sus lotes - lo que pocas veces sucedió-, la "reforma agraria” paramilitar en Urabá se relacionó con frecuencia con el mantenimiento del control o la titularidad de la tierra. Las “donaciones” de tierra a los campesinos no implicaban la entrega del título, sino la posibilidad de poseerla y usarla. Las personas que donaban las tierras normalmente mantenían los títulos, pero la cadena de titularidad de tales tierras era en sí misma difusa, y a menudo incluía títulos falsos y transferencias de títulos de tierras de donde habían sido desplazados otros campesinos. Por tanto, las dudas que esto creaba en aquellos que cultivaban las parcelas eran múltiples: por un lado, la cadena de titularidad de las parcelas donadas no estaba bien definida y, por el otro, no tenían manera de exigir un derecho permanente sobre las tierras que cultivaban. Para los líderes de tales proyectos, lo importante era que los beneficiarios tomaran posesión de la tierra, pues además de servir como proyecto social, dichas posesiones ayudaban a crear una fachada legal con la que los paramilitares cubrían las acciones ilegales cometidas en el proceso de adquisición de la tierra y sus títulos. Las posesiones también significaban la posibilidad de recuperar las parcelas en el futuro para sus propios proyectos agroindustriales, si así lo decidían.

Mientras se llevaban a cabo proyectos paramilitares que involucraban pequeñas posesiones, estaban en marcha otros esfuerzos para acceder a la tierra liderados por movimientos sociales. Al aprobarse la Ley de Justicia y Paz, corrieron rumores en Urabá de que con la desmovilización de los paramilitares se abrirían oportunidades para recuperar algunas de las tierras que las personas habían perdido durante la violencia. Varios grupos de campesinos se embarcaron en esfuerzos a través de las entidades estatales Acción Social y la Fiscalía de Justicia y Paz para tratar de retornar a sus tierras. Pero, tal y como me narró Jairo, un campesino involucrado en dicha iniciativa, los esfuerzos hechos mediante 
los canales formales fueron en gran medida infructuosos, lo que motivó a los campesinos a querer volver a sus fincas por sus propios medios.

No nos abrieron puertas en las instituciones... después de la Ley 975, buscamos ya el acercamiento con Acción Social, que nunca sabía de nada. Eso no, no estaba en la ley, y no nos dieron cabida. Y, con la Fiscalía de Justicia y Paz, que tampoco nos dieron cabida. Entonces lo que hicimos fue, ah bueno, como salió la propaganda engañosa que los que habían perdido su finca podían retornar a su finca... nos dijeron que podemos retornar, jnosotros retornemos solos!... Nadie se iba a meter con nosotros ni nada de eso, como supuestamente entre comillas los paramilitares se habían desmovilizado. Eso fue lo que nos impulsó a hacer eso.

Algunos grupos campesinos, en un principio apoyados por el líder local Benigno Gil, se organizaron para retornar a las fincas que alguna vez les habían pertenecido, en un esfuerzo por "volver a tomar posesión de lo que ha sido, es y seguirá siendo nuestro”, tal como se reportó que había escrito Gil en una carta antes de su muerte ${ }^{20}$. Esos esfuerzos iniciales dieron cabida a la idea de "volver a tomar posesión” de las fincas, la cual fue mantenida como estrategia por varios campesinos en Urabá. La noción de tomar posesión —como acto físico con efectos políticos y potencialmente jurídicos-fue crucial en estos procesos. Al igual que en procesos previos para lograr el acceso a la tierra en Urabá -mediante ocupaciones, posesiones e invasiones-, los campesinos que hicieron parte de la retoma de fincas creían que su presencia y la de sus familiares, así como la siembra de cultivos, podrían asegurar la posibilidad de reclamar la tierra en ausencia de opciones institucionales que les permitieran recuperarlas. Sin embargo, en su valoración inicial de los peligros, no contemplaron la fuerte oposición que enfrentarían. Benigno Gil fue asesinado en el 2008, lo que sacudió al movimiento. En adelante, vendrían más asesinatos de líderes que intentaron reclamar tierras.

Varios años después, cuando el Gobierno comenzó a promover la restitución de tierras en la región, organizaciones como Tierra y Vida, que agrupaba a cientos de familias desplazadas, buscaron otra vez las vías institucionales para reclamar las fincas. Esta organización estuvo involucrada en el proyecto piloto de restitución, el cual se concentró en varias veredas donde había campesinos organizados. Algunos de los lotes que fueron objeto de este proyecto piloto habían formado parte de la ola de invasiones en Urabá durante los ochenta y luego de los desplazamientos a finales de los noventa. Uno de esos lotes se llamaba La

20 Tal carta se cita en "Fue asesinado Benigno Gil, líder social de Urabá que ocupó tierras que le arrebataron los 'paras'”. El Tiempo, 24 de noviembre del 2008. http://www.eltiempo.com/ archivo/documento/CMS-4684874. 
Niña, una finca en la vereda California, que a principios de los ochenta perteneció a Emilio Hasbún, de origen libanés. La llegada temprana de Hasbún desde Santa Marta a Urabá se dio a mediados del siglo XX. En un principio llegó como parte de una empresa que construyó canales para Chiquita con el propósito de secar el suelo para el cultivo del banano. Después invirtió en amplias extensiones de tierra, de las que más adelante obtendría el título de propiedad. Uno de los terrenos estaba en California. En 1984 algunos campesinos, con el argumento de que la tierra no estaba siendo explotada, invadieron y parcelaron esa tierra. En 1999, el Incora declaró la extinción parcial de dominio sobre una parte de la propiedad, lo cual no impidió que la familia Hasbún intentara reclamarla. Raúl Hasbún, hijo de Emilio, quien para entonces no solo era empresario bananero sino también comandante del frente Alex Hurtado del Bloque Bananero de las Autodefensas Unidas de Colombia (AUC), envió a un representante a negociar la tierra con los campesinos para forzarlos a pagar por los lotes. Algunos de los que no pudieron pagar se vieron obligados a abandonarlos, mientras que otros pagaron o descubrieron que la tierra no pertenecía a los Hasbún, sino al Estado (CNRR 2010a). Este caso hizo parte del proyecto piloto de restitución y después del proceso de restitución de tierras.

Sin embargo, cuando la restitución había estado en curso por más de dos años, algunos campesinos de la región comenzaron a cansarse de los procesos institucionales que prometían el regreso a sus tierras. A pesar de las miles de demandas de restitución que se interpusieron en Urabá, hasta septiembre del 2015 los jueces de restitución solo habían publicado 37 fallos sobre los casos en la región ${ }^{21}$. En consecuencia, los campesinos empezaron a reorganizarse para reclamar tierras mediante tomas colectivas, y tomaron posesión de ellas con métodos que muchos habían aprendido en los procesos de invasión de los ochenta y de los esfuerzos colectivos por retomar la posesión durante la década del 2000. Los motivos que guiaban a estos campesinos eran diversos. Algunos, como los que se habían organizado con Benigno Gil, estaban frustrados por la lentitud de las vías institucionales. Para otros, la inspiración era el proceso de restitución mismo, y pensaron que establecerse en las tierras les demostraría a los funcionarios que en realidad las necesitaban. Otros creyeron que con seguridad sus tierras serían restituidas, y que establecerse en ellas era anticiparse al éxito eventual de su caso. A pesar del peligro que implicaban las retomas, y de la oposición que recibieron de la URT, grupos de campesinos se posesionaron en fincas en varias zonas de Urabá. 


\section{Las posibilidades y los límites del despojo}

La sección anterior ofrece una lectura etnográfica de la cuestión de la tierra en una región que se ha convertido durante los últimos años en un lugar caracterizado por ser emblemático del despojo. ¿Cómo nos orienta el despojo, en tanto herramienta conceptual, hacia una comprensión de esta historia sobre la cuestión de la tierra en Urabá?

La narración común de Urabá como un lugar caracterizado por el despojo inicia y termina, por lo general, con la violencia de finales de los noventa. Este fue un momento crucial para Urabá, una época que está en la memoria de todos sus residentes. Los trabajadores, campesinos y habitantes promedio de la región la recuerdan debido a las múltiples pérdidas — de sus familias, sus tierras y sus medios de subsistencia- que sufrieron a consecuencia de la violencia paramilitar. Por su parte, algunos segmentos de la élite en Urabá la recuerdan como un tiempo en que recibieron un alivio de la violencia guerrillera. Un empresario se refirió a esa época como "la paz de los paracos". Sin embargo, entre los distintos grupos sociales hay un entendimiento general de que esta fue una etapa caracterizada por cambios dramáticos en la tenencia de la tierra, un momento en el que la tierra que antes pertenecía a campesinos pasó a manos de grandes terratenientes, un periodo durante el cual pequeñas fincas campesinas se transformaron en grandes fincas ganaderas y en el que la gente sin tierra pobló las invasiones urbanas. Lo que para muchos de los grandes terratenientes fue un tiempo propicio para la inversión, en un contexto nuevo que presentaba circunstancias políticas y económicas favorables, para la mayoría de los habitantes en Urabá fue un tiempo de despojo.

Es entonces comprensible, hasta cierto grado, que cuando el despojo empezó a aparecer con frecuencia en el léxico burocrático, Urabá se convirtiera en el ejemplo a mostrar. Tal atención al despojo abrió paso a una serie de investigaciones - por parte del Estado, la sociedad civil, la prensa y la academia - fundamentales para lograr una comprensión más profunda del paramilitarismo, particularmente sobre la economía paramilitar relacionada con la tierra. Los paramilitares se habían mostrado renuentes a hablar de esos temas durante la desmovilización, pese a que esos asuntos habían definido parte del proyecto paramilitar. Este nuevo enfoque en el despojo también permitió que la infraestructura institucional relacionada con la tierra creciera. Unos años antes, estos importantes cambios políticos en el objeto y en los términos del conocimiento burocrático eran apenas imaginables. 
Pero si bien esa orientación hacia el despojo ha abierto posibilidades políticas, también ha traído limitaciones. En este punto retomo las preguntas motivadas por Gillian Hart que expuse al inicio de este trabajo: ¿el despojo, como concepto, se ajusta a la complejidad de lo que buscamos comprender en la coyuntura actual en Colombia? Aun cuando entendemos las posibilidades que el concepto abre, ¿cuáles podrían ser sus límites como herramienta conceptual para entender el arco del conflicto? Cuando formulo estas preguntas no busco negar la existencia de los hechos materiales que constituyen el despojo. Tampoco busco debatir la importancia crucial del cambio en los espacios institucionales con respecto al estudio del papel que ha desempeñado el despojo en el conflicto y la reparación para aquellos que han sido despojados. Lo que me propongo considerar, junto con las posibilidades que esto abre, son algunas de las limitaciones que puede traer esta nueva mirada sobre el despojo y el campo semántico cada vez más abarrotado que ha aparecido en torno al término a partir de su uso en espacios sociales, académicos y burocráticos. En referencia al importante trabajo de Andrés Salcedo sobre el desplazamiento (Salcedo 2008; 2015) —concepto que, al igual que el de despojo, tomó fuerza con rapidez en una coyuntura crítica en la historia del conflicto-, mi intención es usar la etnografía para considerar otros conceptos que, junto al de despojo, puedan ayudarnos a tratar las complejidades del asunto que intentamos entender.

Vuelvo entonces a la distinción entre el concepto de despojo y la noción de la cuestión de la tierra. ¿Cuáles son las narraciones de la historia que estas dos categorías evocan en un lugar como Urabá? En mi trabajo de campo encontré que la cuestión de la tierra se refería a un complejo grupo de prácticas y eventos históricos relacionados con la tierra, que incluían formas de acceder a ella, como la ocupación, la posesión y la invasión; formas de despojo mediante la violencia y la estafa; y maneras de entender las relaciones con la tierra a través del trabajo, el amor, la familia, la comunidad, la inversión y los medios de subsistencia. La tierra se convierte así en sujeto de planes, sueños y pesadillas, y en objeto de ciclos de tenencia que incluyen tanto el despojo como formas de acceso a la tierra, y que pocas veces se narran exclusivamente como robo o saqueo. El énfasis en el despojo captura elementos de esta historia de la cuestión de la tierra, tales como las formas de violencia y pérdida que marcaron cierto periodo en la región. Pero no abarca una parte de la historia sobre cómo las personas lograron el acceso a sus tierras desde el principio y, por tanto, lo que la tierra ha significado para quienes habitan la región y las múltiples maneras en que se relacionan con ella. Si bien la cuestión de la tierra, al igual que el despojo, tiene su propia y compleja historia — que también implica campos de significados entrelazados y que tiene 
sus propios retos conceptuales-, este asunto emergió en mis entrevistas y conversaciones en Urabá como una categoría más amplia que el despojo y con más posibilidades para capturar las formas y los términos en los que la gente local narra su relación con la tierra. En particular, el uso de la cuestión de la tierra como un término local no solo abarca el acto de quitar la tierra a alguien, que está implicado en el concepto de despojo, sino también las múltiples formas en que la gente accedió a la tierra en la región.

Urabá está marcada por olas de colonización y ciclos de tomas de tierras, algunos de los cuales describo en las historias de posesión, ocupación e invasión que aparecen en la sección anterior. La complejidad de esta historia exige conceptos que nos ayuden a entender los dos lados de la moneda: por una parte el acto de quitar tierras y, por la otra, el acto de tomar la tierra desde un principio. En inglés, la imposibilidad de hablar del despojo sin que simultáneamente se consideren las formas de acceder a la tierra es explícita: el término dispossession (despojo) lleva dentro de sí mismo la noción de possession (posesión). En ese sentido, no se puede pensar el despojo, o la desposesión, sin pensar la posesión. Sugiero que atender a esta dualidad conceptual y pensar las formas de acceder a la tierra - tales como la posesión, la ocupación y la invasión-mientras pensamos el despojo es necesario para entender la complejidad de los asuntos de la tierra en Urabá. Términos tales como posesión desempeñan un papel crucial en la narración local de la cuestión de la tierra que va desde las historias sobre el arribo y el establecimiento de la gente en las zonas rurales y en los centros urbanos, pasa por las maneras en que los asentamientos se convirtieron en sitios de control social para grupos políticos y armados, y llega a los recientes intentos de retomar tierras rurales. La importancia de estos términos en el léxico local está en el papel fundamental que las prácticas de acceso a la tierra, como la posesión y la invasión, han cumplido en la vida económica, la práctica política y la historia social.

Los estudiosos del tema han notado la relevancia que esas formas han tenido en la región en términos de su influencia en la configuración de la vida social, la formación de territorios y en el conflicto mismo. En su análisis sobre las territorialidades en Urabá, Clara Inés Aramburo señala las maneras cruciales en que las formas de colonización de la tierra desde los sesenta hasta los ochenta — por campesinos, grupos étnicos, guerrillas, paramilitares y empresarios- transformaron el surgimiento y la organización de los territorios (Aramburo 2009). Por su parte, Clara Inés García (1996) describe el papel clave que la invasión cumplió para definir formas de organización social, poder y conflicto:

Lo paradójico en el caso de Urabá es que la invasión es uno de los medios más generalizados para tomar posesión de la tierra en un territorio 
supuestamente abierto al proceso colonizador. Así, las invasiones devienen aquí no solo en el factor primero de conflicto social, sino - y en virtud de ello- de configuración de redes de solidaridad, de organización social y de poderes. (80)

El papel crucial que estas formas de acceder a la tierra tuvieron durante la segunda mitad del siglo XX se construyó a partir de la historia previa de Urabá. Claudia Steiner afirma que las aceleradas tomas y adquisiciones de tierra en los sesenta no ocurrieron en un espacio vacío, sino en un territorio que había estado durante mucho tiempo sujeto a una lucha por la tierra. Lo que había sido territorio indígena cuna en el siglo XVI, durante los siglos XVI y XVII recibió el influjo de cimarrones provenientes de minas en el Tapón del Darién. La representación de la región como un lugar que requería ser colonizado para "mejorar la raza” sustentó las colonizaciones posteriores desde Antioquia y el Sinú, a finales del siglo XIX y principios del XX (Steiner 2000), del mismo modo que lo han hecho las nociones de productividad, que siguen presentes en las justificaciones para tomar tierras en la actualidad. El trabajo de Catherine LeGrand (1986) sobre colonización y conflicto en la costa caribe destaca también que formas de acceder a la tierra tales como la invasión estructuraron, desde finales del siglo XIX hasta la reforma agraria de los treinta, los conflictos entre grandes propietarios, arrendatarios, empresarios y campesinos. Las complejas interacciones en la costa entre el despojo y las formas de acceder a la tierra motivaron algunas de las posteriores migraciones desde el Sinú hasta Urabá.

Una narración de una región como Urabá que no conceptualice estas formas de acceder a la tierra - por separado y en su íntima relación con el despojose torna parcial y unidimensional. La importancia crucial que guardan estas formas en Urabá es evidente, incluso para los que han estado intensamente comprometidos con develar los alcances del despojo. La Fundación Forjando Futuros se ha encargado durante varios años de apoyar a los reclamantes de tierras y de documentar el despojo en Urabá. Uno de los primeros boletines de la fundación -que apoya la restitución a escala nacional, pero se basa en las experiencias de restitución en Urabá- incluye en la portada una imagen de la obra Horizontes, de Francisco Antonio Cano (Forjando Futuros 2010). La imagen representa a una mujer, un hombre y un bebé sentados en una montaña. El hombre lleva un morral en su espalda y un hacha en la mano. Su otro brazo se encuentra extendido hacia un lugar distante al cual los tres dirigen su mirada expectante. Esta pieza es una imagen clásica de la colonización antioqueña. En el boletín, su significado no es tan solo el de la colonización de la tierra en Urabá sino también el del retorno a la tierra despojada. En este contexto la imagen refleja, a través de una 
dualidad consciente, la íntima relación entre la amplia gama de formas físicas de acceder a la tierra, a las que en las fincas y calles de Urabá llaman posesión y despojo.

Esta íntima relación entre posesión, en su sentido etnográfico, y despojo - y, de hecho, la imposibilidad de pensar la una sin la otra- está dentro de los mismos regímenes de propiedad que subyacen tanto a la posibilidad de acceso a la tierra como del despojo en Urabá. Las reglas jurídicas permitieron explícitamente las transferencias de propiedad entre el Estado y actores privados por medio de formas de acceso a la tierra como la ocupación de baldíos. También facilitaron los cambios de titularidad de una persona a otra mediante el concepto jurídico de la prescripción, acto que para el beneficiario es una forma de acceder a la tierra a través de la posesión bajo ciertas condiciones jurídicas, pero que puede ser entendido como despojo por la persona que deja de ser propietaria. En algunos casos, el aval de dichas transferencias entre individuos provenía de reglas jurídicas que autorizaban la extinción de dominio de los dueños y la entrega de títulos a quienes se habían instalado en la tierra. Este acto puede entenderse como una conjunción de posesión y despojo. Aunque la invasión no es un acto legal, la frecuencia con la que la gente logró titular la tierra luego de las invasiones la llevó a convertirse en una práctica política que simultáneamente contenía el despojo y formas de acceder a la tierra. En otro trabajo discuto la relación íntima, doble y cíclica entre posesión y despojo como una que podría ser entendida como des/posesión (Morris n. d.).

Las maneras en que el despojo se ve facilitado por las normas jurídicas hacen parte de la misma estructura de la institución de la propiedad. Carol Rose (2000) describe cómo los regímenes de propiedad tienen en su estructura innumerables "rupturas" que permiten la extinción de los derechos de propiedad mediante mecanismos cotidianos como la compra y venta, las regulaciones que autorizan cosas como la prescripción adquisitiva de dominio o la expropiación, y por circunstancias extraordinarias como la guerra o la revolución. Muchas de estas figuras implican procesos tanto adquisitivos como de despojo. En ellos no se definen estrictamente actores buenos y malos, y los regímenes de propiedad crean zonas grises intencionales que sirven de válvulas de escape para evitar los problemas sociales que podrían surgir de regímenes de propiedad que no permitieran ninguna forma de expropiación. Las decisiones en torno a los derechos dentro de estas zonas grises están justificadas por intereses tales como la utilidad pública, la productividad o la justicia, que triunfan sobre una regla de propiedad en blanco y negro que prohíbe toda expropiación. 
La aplicación del concepto de despojo como uno de los elementos que definen la reparación a las víctimas en la Ley de Víctimas es un ejemplo de esas rupturas en el derecho de propiedad, y es simultáneamente un ejemplo de la creación de actores buenos y malos estrictamente definidos. Por un lado, la posibilidad de restitución es una legalización explícita del acto de quitarles tierras a quienes actualmente las poseen. Como describe Rose (2000), se trata de una ruptura basada en el reconocimiento de las circunstancias extraordinarias de la guerra y de la necesidad de reparar a quienes la han padecido. Por otra parte, esta posibilidad no está justificada por grandes objetivos como la justicia o la equidad, sino en la calificación de víctimas definidas y de presuntos victimarios dentro de un lapso específico durante el conflicto. Apenas se determina el despojo de una víctima dentro de ese periodo, dejan de existir las zonas grises a través de las cuales se podrían introducir juicios basados en objetivos más amplios. Aunque una persona que se oponga al proceso demuestre su buena fe y reciba una compensación por las tierras que se le quitaron, su propia condición de víctima registrada con el Estado no activa una consideración de factores tales como la justicia o la equidad, dada la estricta asignación del derecho a la víctima que, según se ha determinado, fue despojada. La aplicación del concepto de despojo a una noción pura de la víctima hace del proceso continuo y cíclico de posesión y despojo, que ha tenido lugar durante décadas de conflicto, una cuestión de víctimas y victimarios definidos en un momento determinado de la historia. También obliga a que la identidad de los reclamantes esté asociada con una condición de daño (Brown 1995) y no con una de política, aun cuando la invasión previa motivada por la política fuera la razón por la cual pudieron reclamar la tierra en un principio.

La forma particular que ha ido tomando el despojo en el discurso jurídico y burocrático tiene consecuencias no solo conceptuales, sino también políticas. La conexión del despojo con la condición de víctima sugiere que los procesos de despojo son unidimensionales y evoca un imaginario del conflicto en el cual los paramilitares les quitaron la tierra a los campesinos y todavía conservan esas tierras a las que los campesinos desean volver. Sin embargo, en los primeros años del proceso de restitución, quedó claro que, si bien este imaginario del problema lo describe parcialmente, las cosas son mucho más complicadas. En primer lugar, los límites de tiempo impuestos para la restitución significaron que la gente que perdió sus tierras a causa del conflicto antes de 1991 —en Urabá esto muchas veces se refiere a los despojos facilitados por la guerrilla- no calificó como víctima de despojo. En segundo lugar, el imaginario de que los lotes despojados siguen en poder de los despojadores paramilitares o de los grandes propietarios simplemente no encajó con varios de los casos de restitución. Dada la 
complejidad de las formas de acceder a la tierra de los campesinos después de la violencia paramilitar de finales de los noventa, los funcionarios y jueces de restitución se vieron enfrentados a casos en donde estaban quitándoles tierras a campesinos pobres y desplazados que habían estado cultivándolas desde principios de la década del 2000 para restituirlas a otros campesinos pobres y desplazados que habían sido expulsados de la tierra a finales de los noventa. Estas ambigüedades inherentes al conflicto, y las formas relacionadas de la posesión y el despojo que habían surgido en el amplio arco de la guerra, eran simplemente demasiado complicadas para la estrecha perspectiva del bien y el mal que había surgido de la conexión entre el despojo y la condición de víctima. Esta conceptualización del despojo, por lo tanto, comenzó a tener costos importantes en términos de una comprensión y de un reconocimiento político de las realidades complejas y multidimensionales de la guerra.

\section{Conclusión}

Quiero sugerir que el despojo por sí solo es inadecuado para abordar la complejidad con la que estamos tratando de lidiar. Lo es particularmente en los lugares que se han vuelto "emblemáticos" del despojo: en las denominadas fronteras o tierras de nadie de la Nación. Margarita Serje describe cómo esas regiones fueron diagnosticadas como periferias conflictivas que debían articularse a la Nación y señala que este imaginario se hace posible gracias a la producción del "contexto", por medio del cual la gente y los paisajes de regiones específicas son producidos como los otros de la Nación moderna, oscureciendo así la multidimensionalidad detrás de la alteridad (Serje 2005). Sugiero que esa mirada contribuyó a la conversión de Urabá en un sitio emblemático del despojo. Esto activó un conjunto de formas de entender y gestionar una periferia problemática que, con suficiente intervención, podría finalmente ser disciplinada y ordenada.

En vez de esa aproximación, vendría bien complementar la comprensión del despojo con otras herramientas conceptuales que nos ayuden a leer los sedimentos de las historias en lugares como Urabá, para entenderlos en su complejidad y no simplemente como emblemáticos del despojo. Sin perder de vista que los conceptos migran entre los espacios sociales, académicos y burocráticos, construir un conjunto más amplio de referentes mediante un trabajo etnográfico sostenido, con énfasis en los términos que la gente usa para hacer su política, podría contribuir no solo a elaborar una historia o un trabajo conceptual más 
adecuado, sino a tener las herramientas para construir resultados políticos mejores y más duraderos.

La antropología de la propiedad provee abundantes recursos para llevar a cabo un trabajo como este, ya que concentra su atención en la importancia de construir los conceptos desde las relaciones y términos sociales que subyacen y emergen de las relaciones de propiedad. Trabajos como el de Malinowski ([1935] 1978), sobre las prácticas hortícolas de los Trobriand (en el que enfatiza la importancia de ir más allá del marco jurídico de las relaciones de propiedad para interrogar los principios de la vida social subyacentes), y el análisis de Max Gluckman (1965), sobre las formas del estatus y las obligaciones sociales de los estates of administration (que estaban en la base de la propiedad de la tierra entre los Barotse), proporcionan principios fundamentales para este tipo de elaboraciones conceptuales guiadas por la etnografía. Trabajos más recientes en la antropología de la propiedad se adhieren a esos principios para rechazar eventualmente la utilidad conceptual de la propiedad (Strathern 1999) - y otros conceptos relacionados, como los derechos de propiedad estrictamente individuales (Verdery 1999) — en sitios particulares, y para construir a su vez herramientas conceptuales alternativas basadas en las relaciones y en los términos relevantes para la vida social local.

Al menos en Urabá, una ruta para construir estas herramientas conceptuales complementarias es prestar atención a las múltiples relaciones con la tierra que están implícitas en la cuestión de la tierra en la región, entre ellas, el despojo, pero también las formas de acceder a la tierra como la posesión. En las narrativas burocráticas del despojo, formas de acceder a la tierra como la invasión o la posesión han sido, en gran medida, relegadas a instancias de tenencia informal, susceptibles de convertirse en títulos formales a través de la restitución. Pero esas formas de acceder a la tierra han desempeñado en la región un papel mucho más importante como modos de construcción de política, como prácticas de poder, como estrategias para crear mercados, como maneras de sostener familias y comunidades, como lugares de trabajo o de inversión, como rutas hacia la base política o social y como elementos cruciales de la acción cotidiana de la guerra y de la forma en que se ha desarrollado en relación con la tierra.

La posesión es la otra cara del despojo, pero también contiene diferentes significados e implicaciones políticas. Además de permitirnos entender el acceso, hace posible pensar la autoposesión y considerar a las personas como sujetos políticos complejos, en lugar de simplemente inscribirlas en un mundo de víctimas y victimarios del despojo. Este es el tipo de cambio que Andrés Salcedo defiende cuando usa términos como construcción y reconstrucción para entender la política y el lugar de las personas desplazadas, al complementar los conceptos 
de víctima, trauma y crisis con otros términos que permiten ver el papel de las poblaciones desplazadas en la construcción de la ciudad (Salcedo 2015). Mientras que Judith Butler y Athena Athanasiou (2013) advierten los peligros de oponerse al despojo a través de una lógica de posesión - para evitar una valorización del individualismo posesivo (sea del ser o de una cosa)—, las lógicas de la posesión que emergen en Urabá no son solo individuales ni simplemente giran en torno al reconocimiento, sino que pueden ser formas políticas y relacionales de ser y de tener. La posesión, entonces, se vuelve no únicamente la contrarreclamación individual del despojo, sino una práctica política relacional y multivalente por derecho propio.

Me parece que, en la coyuntura actual, la elaboración de conceptos complementarios como estos se hace posible, en parte, poniendo atención a las dinámicas mutuamente constitutivas de acceso a la tierra urbana y rural. Si bien la noción de despojo se ha atrincherado como una manera de conceptualizar los efectos del conflicto sobre la tierra rural, no se ha convertido en un modo legal o burocrático predominante para narrar la dinámica del suelo urbano, ni siquiera en Urabá. Esto indica, por un lado, una falta de atención estatal a los niveles de violencia, al desplazamiento intraurbano y a la pérdida de tierras y hogares que ha afectado a muchos barrios urbanos. Pero, por otro lado, abre el campo conceptual de una manera que permite diferentes interpretaciones de estos espacios como lugares quizás de despojo, pero también de construcción y de política. Esa construcción y esa política a menudo están relacionadas con la dinámica de la posesión y el despojo de la tierra en las zonas rurales que rodean estos sitios urbanos, tal como sucede en Urabá. Una mayor atención a esta relación, entendida no solo como de migración rural-urbana debida al despojo sino también como una política de posesión, podría ayudar a construir las herramientas conceptuales complementarias necesarias para entender las dinámicas multidimensionales que conforman algo como la cuestión de la tierra en Urabá. Este es el tipo de análisis que se necesita -y no solo un mapeo de cómo se entiende el despojo rural sobre lo urbano- si queda alguna esperanza de lidiar con las dinámicas de la tierra y del conflicto de una manera que conduzca a la construcción de soluciones reales y duraderas. 


\section{Agradecimientos}

Primero, agradezco a las personas de Urabá, quienes me han abierto sus casas y corazones desde mi primera visita a la región en 2009. Aunque no las nombro en este artículo para proteger su identidad, esta investigación no hubiera sido posible sin ellas. Agradezco a Julio Arias Vanegas, Alhena Caicedo Fernández, al equipo editorial de la Revista Colombiana de Antropología y a los dos evaluadores anónimos por sus comentarios sobre las versiones anteriores de este artículo. Mis agradecimientos a Sonia Serna por su excelente traducción del artículo al español. Gracias a Alejandra Azuero, Diana Bocarejo, Lee Cabatingan, Jean Comaroff, John Comaroff, Nate Ela, Eric Hirsch, Duncan Kennedy, Amy McLachlan, Erin Moore, Stephan Palmié, Justin Richland, Diana Rodríguez Franco, Paula Rodríguez R., Jeremy Siegman, Kaushik Sunder Rajan, Christien Tompkins y Austin Zeiderman por las conversaciones que me ayudaron a construir y mejorar estos argumentos. Agradezco a mis colegas de Dejusticia y a la Facultad de Derecho de la Universidad de los Andes, donde estuve afiliada durante mi investigación, por muchos años de colaboraciones productivas. Distintas etapas de esta investigación fueron financiadas por el Social Science Research Council, la Wenner-Gren Foundation, la Inter-American Foundation, la Land Deal Politics Initiative y el Center for Latin American Studies, Department of Anthropology y Pozen Family Center for Human Rights de la Universidad de Chicago.

\section{Referencias}

Agudelo, Mario. 2005. Qué pasa en Cuba que Fidel no se afeita: de las armas a la esperanza. Un diálogo con Jaime Jaramillo Panesso. Medellín: Fondo Editorial ITM.

Aparicio, Juan Ricardo. 2009. “La 'mejor esquina de Sur América’: aproximaciones etnográficas a la protección de la vida en Urabá”. Antípoda 8: 87-115.

Aramburo Siegert, Clara Inés. 2009. "La tensa interacción entre las territorialidades y el conflicto armado, Urabá 1960-2004”. Controversia 192: 81-119.

Botero, Fernando. 1990. Urabá: colonización, violencia y crisis del Estado. Medellín: Universidad de Antioquia.

Brown, Wendy. 1995. States of Injury: Power and Freedom in Late Modernity. Princeton, New Jersey: Princeton University Press. 
Bucheli, Marcelo. 2005. Bananas and Business: The United Fruit Company in Colombia, 18992000. Nueva York: New York University Press.

Butler, Judith y Athena Athanasiou. 2013. Dispossession: The Performative in the Political. Cambridge: Polity Press.

Centro Nacional de Memoria Histórica (CNMH). 2013a. iBasta ya! Colombia: memorias de guerra y dignidad. Bogotá: Centro Nacional de Memoria Histórica.

-. 2013b. Esbozo de una memoria institucional: la política de reforma agraria y tierras en Colombia. Bogotá: Centro Nacional de Memoria Histórica.

Comisión de Seguimiento a la Política Pública sobre Desplazamiento Forzado (Comisión de Seguimiento). 2008. VI Informe a la Corte Constitucional: "La restitución como parte de la reparación integral de las víctimas del desplazamiento en Colombia. Diagnóstico y propuesta de líneas de acción”. Bogotá: Comisión de Seguimiento a la Política Pública sobre Desplazamiento Forzado.

Comisión Nacional de Reparación y Reconciliación (CNRR). 2009. El despojo de tierras y territorios. Aproximación conceptual. Bogotá: Comisión Nacional de Reparación y Reconciliación, Área de Memoria Histórica.

-.2010a. Proyecto piloto de restitución de tierras en Turbo: el desplazamiento forzado, las tipologías del despojo y las rutas para la restitución. Bogotá: Comisión Nacional de Reparación y Reconciliación.

- 2010b. La tierra en disputa: memorias del despojo y resistencias campesinas en la costa caribe, 1960-2010. Bogotá: Taurus.

Fals Borda, Orlando. 1986. Retorno a la tierra: historia doble de la costa. Tomo 4. Bogotá: Carlos Valencia Editores.

Forjando Futuros. 2010. "La restitución de tierras sí es posible en Colombia”. Boletín Informativo sobre la Restitución de Tierras. http://forjandofuturos.org/documentos/publicacionrestitucion-de-tierras-la-restitucion-si-es-posible_150-primeras-sentencias_septiembre -2013-fundacion-forjando-futuros.pdf.

García, Clara Inés. 1996. Urabá: región, actores y conflicto, 1960-1990. Medellín: INER.

Gluckman, Max. 1965. The Ideas in Barotse Jurisprudence. Manchester: Manchester University Press.

Hart, Gillian. 2006. "Denaturalizing Dispossession: Critical Ethnography in the Age of Resurgent Imperialism”. Antipode 38 (5): 977-1004.

Hinestroza, Gabriel Harry. 2015. "La mejor esquina de América”. El Colombiano, 25 de febrero. http://www.elcolombiano.com/opinion/columnistas/la-mejor-esquina-de-americaCE1363510.

Instituto Colombiano de Antropología e Historia (ICANH). 2015. "Antropologías del despojo en Colombia I”. Revista Colombiana de Antropología 52 (2). https://sites.google.com/ site/ccsociedad/ccsociedad/convocatorias/convocatoriarcaantropologiasdeldespojoencolombiavolumen522de2016. 
LeGrand, Catherine. 1986. Frontier Expansion and Peasant Protest in Colombia, 1850-1936. Albuquerque: University of New Mexico Press.

Malinowski, Bronislaw. (1935) 1978. Coral Gardens and their Magic: A Study of the Methods of Tilling the Soil and of Agricultural Rites in the Trobriand Islands. Nueva York: Dover Publications.

Morris, Meghan L. n. d. "Property in the Shadow of the 'Post-Conflict”". Hot Spots, Cultural Anthropology. Consultado el 30 de abril del 2015. https://culanth.org/fieldsights/667-property-in-the-shadow-of-the-post-conflict.

Ortiz Sarmiento, Carlos Miguel. 1995. Urabá: tras las huellas de los inmigrantes, 1955-1990. Bogotá: Instituto Colombiano para el Fomento de la Educación Superior.

—. 2007. Urabá: pulsiones de vida y desafíos de muerte. Medellín: La Carreta.

Parsons, James. 1967. Antioquia's Corridor to the Sea: A Historical Geography of the Settlement of Urabá. Berkeley: University of California Press.

Pérez, Jesús María. 2010. Luchas campesinas y reforma agraria: memorias de un dirigente de la ANUC en la costa caribe. Bogotá: Puntoaparte Editores.

Rodríguez Garavito, César y Diana Rodríguez Franco. 2010. Cortes y cambio social: cómo la Corte Constitucional transformó el desplazamiento forzado en Colombia. Bogotá: Dejusticia.

Romero Ospina, Roberto. 2011. Unión Patriótica: expedientes contra el olvido. Bogotá: Centro de Memoria, Paz y Reconciliación.

Romero Vidal, Mauricio, ed. 2007. Para-política. La ruta de la expansión paramilitar y los acuerdos políticos. Bogotá: Corporación Nuevo Arco Iris.

-. 2011. La economía de los paramilitares. Redes de corrupción, negocios y política. Bogotá: Debate.

Rose, Carol M. 2000. "Property and Expropriation: Themes and Variations in American Law”. Utah Law Review 1: 1-38.

Salcedo Fidalgo, Andrés. 2008. "Defendiendo territorios desde el exilio: desplazamiento y reconstrucción en Colombia contemporánea”. Revista Colombiana de Antropología 44 (2): 309-335.

—. 2015. Víctimas y trasegares: forjadores de ciudad en Colombia 2002-2005. Bogotá: Universidad Nacional de Colombia, Centro de Estudios Sociales (CES).

Serje, Margarita. 2005. El revés de la nación: territorios salvajes, fronteras y tierras de nadie. Bogotá: Ediciones Uniandes.

Steiner, Claudia. 2000. Imaginación y poder: el encuentro del interior con la costa en Urabá, 1900-1960. Medellín: Editorial Universidad de Antioquia.

Strathern, Marilyn. 1999. Property, Substance, and Effect: Anthropological Essays on Persons and Things. Londres: Athlone Press.

Unidad de Restitución de Tierras (URT). 2014. Informe de rendición de cuentas correspondiente al año 2013. Medellín: Unidad Administrativa Especial de Gestión de Restitución de Tierras Territorial Antioquia. 
Uribe, María Teresa. 1992. Urabá: ¿región o territorio? Medellín: Instituto de Estudios Regionales.

Verdery, Katherine. 1999. Fuzzy Property: Rights, Power, and Identity in Transylvania's Decollectivization. In Uncertain Transition: Ethnographies of Change in the Postsocialist World. Oxford: Rowman \& Littlefield Publishers.

Verdery, Katherine y Caroline Humphrey, eds. 2004. Property in Question: Value Transformation in the Global Economy. Londres: Berg.

Von Benda-Beckmann, Franz, Keebet von Benda-Beckmann y Melanie G. Wiber. 2006. Changing Properties of Property. Oxford: Berghahn Books.

Zamosc, León. 1987. La cuestión agraria y el movimiento campesino en Colombia: luchas de la Asociación Nacional de Usuarios Campesinos (ANUC), 1967-1981. Bogotá: Cinep. 